\title{
Gastroepiploic arteriovenous shunt as a salvage treatment for hepatic artery occlusion after living donor liver transplantation
}

\author{
Seong Hoon Kim, Sang Jae Park \\ Center for Organ Transplantation, National Cancer Center, Gyeonggi-do, Republic of Korea \\ Correspondence to: Seong Hoon Kim, MD, PhD. Center for Organ Transplantation, National Cancer Center, 111 Jungbalsan-ro, Ilsandong-gu, \\ Goyang-si, Gyeonggi-do 410-769, Republic of Korea. Email: kshlj@hanmail.net; kshlj@ncc.re.kr.
}

Submitted Jan 08, 2021. Accepted for publication Mar 11, 2021.

doi: $10.21037 / \mathrm{hbsn}-21-6$

View this article at: http://dx.doi.org/10.21037/hbsn-21-6

Hepatic artery occlusion (HAO) is a calamitous vascular complication following living-donor liver transplantation (LDLT) leading to graft loss with a high mortality (1). Retransplantation is considered when revascularization fails, but may impose heavy burdens in terms of donor shortage and ultra-major surgery.

When all options for arterial reconstruction or retransplantation are considered impossible, portal vein arterialization can be a salvage technique (2).

A 51-year-old man underwent LDLT for hepatocellular carcinoma and Hepatitis B virus-related liver cirrhosis. The right liver graft from his 20-year-old daughter was harvested as previously reported (3). The graft weight was $604 \mathrm{~g}$, and the actual graft-to-recipient weight ratio was $1.06 \%$. In the recipient, portal vein and hepatic vein were reconstructed with two sizable tributaries of middle hepatic vein. The donor's single right hepatic artery of $1 \mathrm{~mm}$ in diameter was anastomosed with the recipient's counterpart of $1.5 \mathrm{~mm}$ in diameter. Duct-to-duct biliary reconstruction was done.

The patient had an uneventful postoperative course. Routine follow-up computerized tomography (CT) on postoperative day (POD) 14 showed no abnormal findings. All hepatic vessels were patent with no hepatic duct dilatation. However, on POD 16, hepatic artery flow was not detected on Doppler ultrasonography. Immediatelyperformed angiography diagnosed acute thrombotic HAO, and catheter directed thrombolysis with recombinant tissue plasminogen activator and heparin fully recovered hepatic artery flow. On POD 23, hepatic artery flow was undetected again. Catheter-directed thrombolysis failed to recover artery flow. So hepatic artery stenting was planned. The stent was passed through the artery anastomosis and placed close to the graft, but subsequent intimal dissection from the origin of common hepatic artery extending into the graft intraparenchymal artery caused complete arterial occlusion with the stent in situ. Further radiologic interventions were unfeasible.

Immediate re-exploration was performed. No redo artery reconstruction was possible because the stent was too tightly compacted up into the intragraft artery to be removed. There was no donor candidate for re-transplantation. The only option available was to create portal vein arterialization.

Considering the same operative field and similar vessel size, the right gastroepiploic artery and vein were mobilized over $5 \mathrm{~cm}$ from the greater curvature of the stomach. The gastroepiploic artery was anastomosed to the vein microscopically in an end-to-end fashion with 8-0 Nylon (Figure 1A). Doppler ultrasonography showed no difference in portal flow between before and after the shunt formation, so no additional modulation was performed intraoperatively. The operative time was $154 \mathrm{~min}$, and the estimated blood loss was $50 \mathrm{ml}$.

On the day before the arteriovenous shunt, the AST level was $571 \mathrm{U} / \mathrm{L}$ and the ALT level was $671 \mathrm{U} / \mathrm{L}$. On POD 1, these levels were 156 and $361 \mathrm{U} / \mathrm{L}$, respectively; on POD 3, 57 and $135 \mathrm{U} / \mathrm{L}$, respectively; on POD 7, 46 and $61 \mathrm{U} / \mathrm{L}$, respectively. The serum total bilirubin levels were elevated to $1.9 \mathrm{mg} / \mathrm{dL}$ on POD 3 but decreased gradually within normal limit on POD 7. On POD 3, CT revealed some focal ischemic change with biloma in the graft. Otherwise, the patient's postoperative course was uneventful. On POD 15, he was discharged. On POD 90, CT scan showed that the portal vein was enhanced through the gastroepiploic 

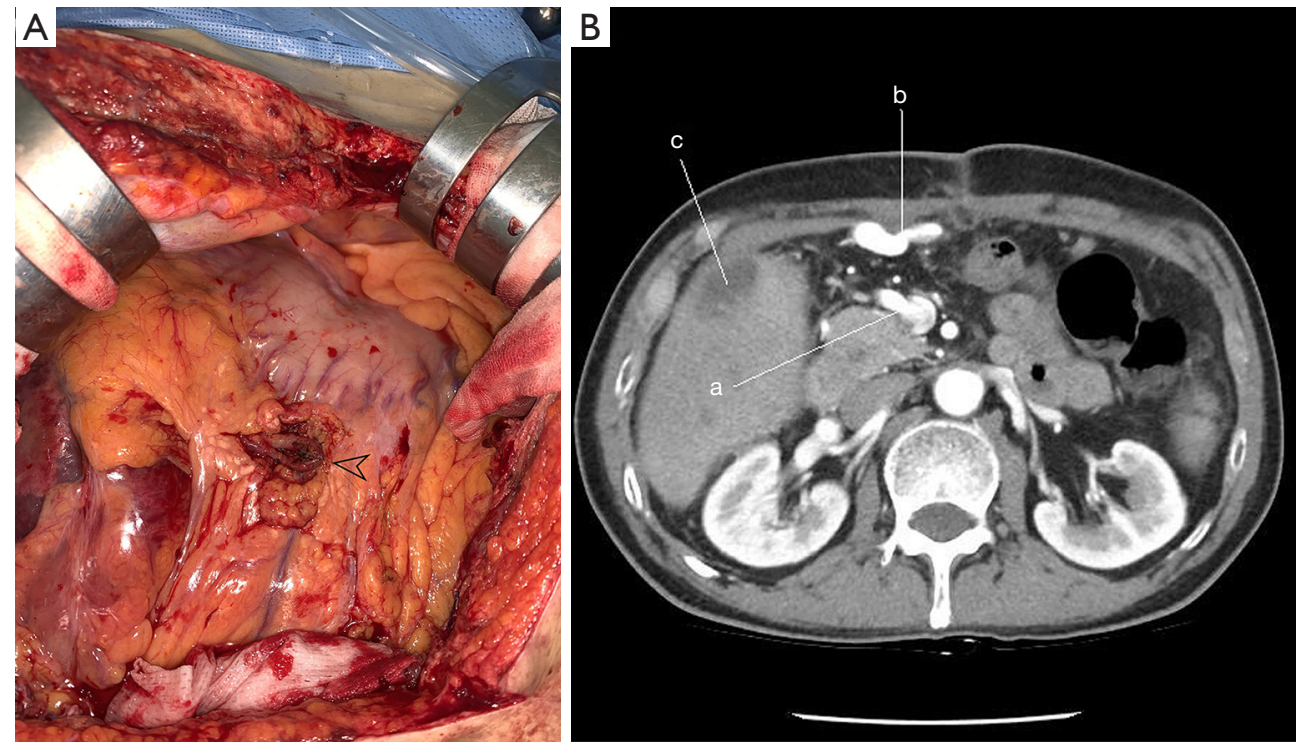

Figure 1 Operative view (A) of right gastroepiploic arteriovenous shunt. The gastroepiploic artery was anastomosed to the vein microscopically in an end-to-end fashion (arrowhead). CT scan (B) showing the right gastroepiploic vein draining into the superior mesenteric vein (a) enhanced through the gastroepiploic arteriovenous shunt (b) at the arterial phase and with focal biloma (c) on POD 90.

arteriovenous shunt at the arterial phase with no change of asymptomatic biloma (Figure 1B).

During postoperative one-year, no collateral arterial flow has been confirmed by CT angiography, and esophageal varices had not progressed on upper gastrointestinal endoscopy. with no signs of portal hypertension. The patient has had no signs of portal hypertension so far and is currently doing well in good health with normal liver function.

This is the first report using right gastroepiploic arteriovenous shunt in an end-to-end fashion for partial portal vein arterialization as a salvage treatment for complete artery occlusion after LDLT that have shown favorable clinical outcomes.

The HAO in this case was iatrogenic. The artery dissection involving both sides of anastomosis, even extending into the graft, was caused accidentally by stent placement in a small-caliber hepatic artery. Revision of anastomosis even using extra-anatomical source for artery flow or retransplantation were impossible. Therefore, the patient had no choice but partial portal arterialization.

The use of gastroepiploic vessels had several advantages. The artery was similar to the graft artery in size, so artery flow into the portal circulation was expected to be neither excessive nor insufficient. Postoperatively the liver function has been good without any clinically apparent manifestations of portal hypertension such as variceal changes of the veins or ascites. The surgical field used the same previous incision avoiding the hepatic hilum. It is easy to access and dissect the vessels from the greater curvatures of stomach without affecting stomach.

In this patient, arteriovenous anastomosis was created in an end-to-end fashion. So, the artery blood from can flow linearly and smoothly into portal vein. If the anastomosis had been done in a side-to-side or end to side fashion, artery flow could have mixed with venous blood that would cause irregular fluctuations or turbulence of flow, which can increase the risk of thrombosis or occlusion of the shunt.

In LDLT, four cases of partial portal arterialization for hepatic arterial occlusion after LDLT were reported (4). Partial portal arterialization was performed by constructing an arteriovenous shunt using mesenteric vascular branches in a side-to-side anastomosis. Two patients died within 50 days after partial portal arterialization. The other two patients didn't maintain the arteriovenous shunt. One had spontaneous closure with hepatopetal collateral arterial flow developed 45 days after partial portal arterialization. The other had the shunt surgically occluded due to portal hypertension 152 days after partial portal arterialization.

Although this shunt for partial portal arterialization has not sufficiently been corroborated in many patients, at least it could be used as a means of extending graft 'lifetime' while awaiting 
retransplant. The major concern in performing portal vein arterialization a risk of delayed portal hypertension, therefore long-term observations are mandatory.

This case provides a good example to show that favorable clinical outcomes could be achieved after partial portal vein arterialization with right gastroepiploic arteriovenous shunt in an end-to-end fashion as a salvage treatment for HAO after LDLT.

\section{Acknowledgments}

Funding: None.

\section{Footnote}

Provenance and Peer Review: This article was a standard submission to the journal Hepatobiliary Surgery and Nutrition. The article did not undergo external peer review.

Conflicts of Interest: Both authors have completed the ICMJE uniform disclosure form (available at https://hbsn. amegroups.com/article/view/10.21037/hbsn-21-6/coif). The authors have no conflicts of interest to declare.

Ethical Statement: The authors are accountable for all aspects of the work in ensuring that questions related to the accuracy or integrity of any part of the work are appropriately investigated and resolved. Written informed consent was obtained from the patient for publication of this manuscript and any accompanying images. The present study was approved by the Institutional Review Board of National Cancer Center in Korea (NCC2020-0316).

Open Access Statement: This is an Open Access article distributed in accordance with the Creative Commons Attribution-NonCommercial-NoDerivs 4.0 International License (CC BY-NC-ND 4.0), which permits the noncommercial replication and distribution of the article with the strict proviso that no changes or edits are made and the original work is properly cited (including links to both the formal publication through the relevant DOI and the license). See: https://creativecommons.org/licenses/by-nc-nd/4.0/.

\section{References}

1. Bekker J, Ploem S, de Jong KP. Early hepatic artery thrombosis after liver transplantation: a systematic review of the incidence, outcome and risk factors. Am J Transplant 2009;9:746-57.

2. Bhangui P, Salloum C, Lim C, et al. Portal vein arterialization: a salvage procedure for a totally dearterialized liver. The Paul Brousse Hospital experience. HPB (Oxford) 2014;16:723-38.

3. Kim SH, Kim YK. Living donor right hepatectomy using the hanging maneuver by Glisson's approach under the upper midline incision. World J Surg 2012;36:401-6.

4. Hayashi H, Takamura H, Tani T, et al. Partial portal arterialization for hepatic arterial thrombosis after livingdonor liver transplant. Exp Clin Transplant 2012;10:247-51.
Cite this article as: Kim SH, Park SJ. Gastroepiploic arteriovenous shunt as a salvage treatment for hepatic artery occlusion after living donor liver transplantation. HepatoBiliary Surg Nutr 2021;10(3):421-423. doi: 10.21037/hbsn-21-6 